\title{
Short-Tailed Shrew Records
}

By ROBERT W. NERO, Saskatchewan Museum of Natural History

Mrs. J. Hubbard off Grenfell, Sasktchewan, recently submitted to the Iuseum a Short-tailed Shrew (Blarna brevicauda) which was collected y her at Grenfell on June 19, 1957. his specimen provides an important erification of the occurrence of Blarina within the known range, renfell being the locality from which this shrew was first reported or the province although no specihen was then available (see Blue ay 1956, vol. 14: 45).

A Short-tailed Shrew (skin and kull) received from James Luthi, axidermist and amateur naturalist, unnichy, and taken by him from a at in July, 1954 extends the range reviously described. Since this recrd is 40 miles north of the Qu'Apelle River valley it adds further veight to the belief that this shrew ccurs over a wider area than is now nown. It would be of particular inerest to obtain records from Wat- rous, Humboldt or Melfort since it seems likely that the range extends at least this far west. Somewhere in this general area one-expects to find the limit of their range and this boundary has special ecological significance.

Another specimen brought in shortly before the Blue Jay went to press extends the known range of Blarina in Saskatchewan northward more than 37 miles. This shrew was found dead on July 23, 1957 in the yard of Bruce Smith of Connell Creek, eight miles northeast of Arborfield, Sask, and was brought to the museum by J. D. Smith of Regina. Presumably, it was caught and left in the yard by a cat, shrews generally seeming to be unpalatable.

A comparable record for Manitoba has just been published in the Canadian Field-Naturalist (vol, 71: 83) extending the range northward in Manitoba to The Pas.

\section{New Silver-haired Bat Records}

By ROBERT W. NERO, Saskatchewan Museum of Natural History

A few Saskatchewan Silver-haired Bats (Lasionycterus noctivagans) lave already been received by the Iuseum this year. The first of these of particular interest since it was aken nearly three weeks earlier in he season than any previous record see BLUE JAY 1957, vol. 15:38-41, $6,86)$ :

pecimen-May 13, 1957, Birminglam, in Pool elevator. Mrs. Steve Curchak. (Female, 2 embryos, crownump measurements - $7 \mathrm{~mm}$.).

pecimen-June 4, 1957, Kamsack, n School. Mrs. I. Podovinnikoff, Linen Valley School. (Female, 2 embyos, $9 \mathrm{~mm}$.).

pecimen-June 10, 1957, Spirit ake, on garage door. Miss Joyce unn. (Female, 2 embryos, $8 \mathrm{~mm}$.). These records suggest that the ilver-haired Bat occurs as a breedng species in the southern part of he province, as was indicated in a revious article. It seems unlikely hat these pregnant females would till have been migrating; moreover, heir appearance within buildings in une suggests attempts to find suitble nursery sites.

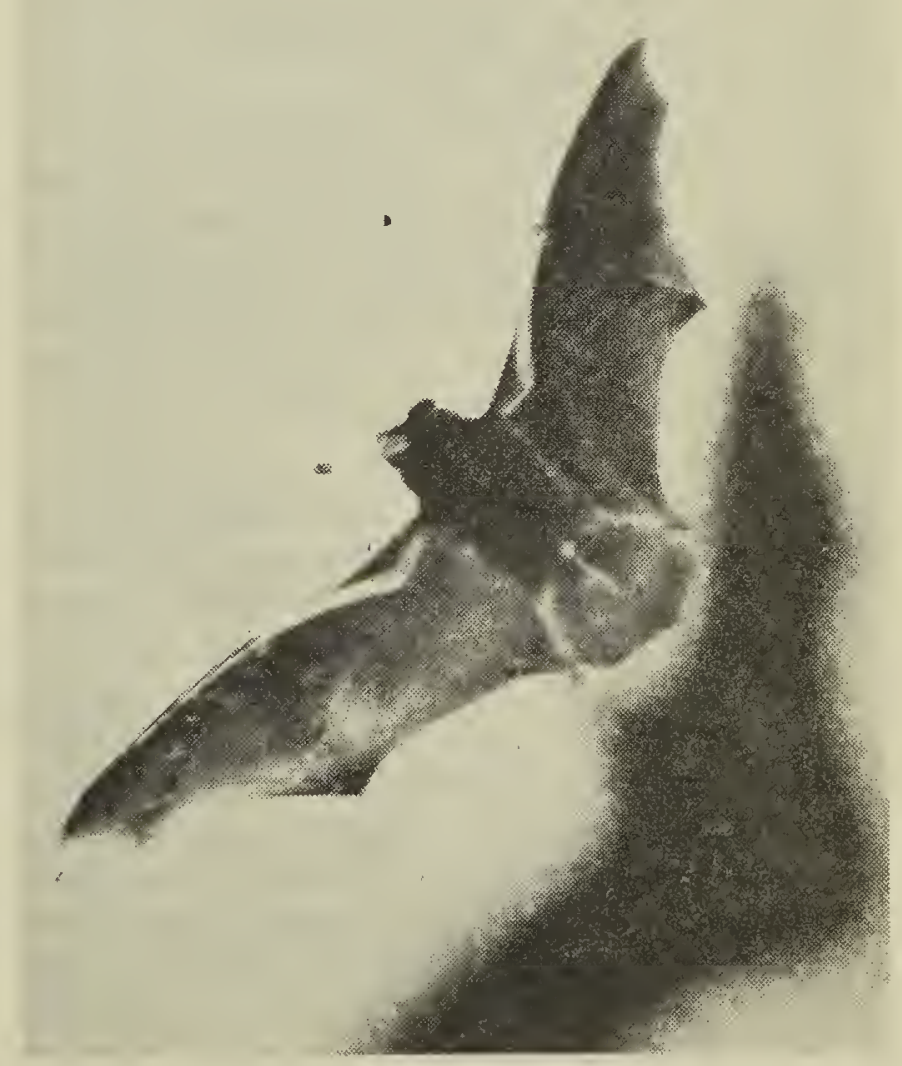

Photo by R. W. Fyfe Live Silver-haired Bat in flight in Museum Board Room. Electronicflash $1 / 1000$ at f11. 